difficult to establish for the other 11 , but there was no clear evidence for cause and effect.

When considering aetiology, an important point is that many of the features described in discussions of catatonic phenomena are also characteristic of autistic disorders. This has interesting implications for the nature of autism and catatonia, and their relationship to each other and to other psychiatric conditions associated with impairments of motor function. This will be the subject of a separate paper.

L.Wing Centre for Social and Communication Disorders, Elliot House, II3 Masons Hill, Bromley, Kent BR2 9HT

A. Shah Leading Edge Psychology, I The Close, Dale Road, Purley, Surrey CR8 2EA

\section{In-patient detoxification after GHB dependence}

Gamma-hydroxybutyrate (GHB) occurs naturally in the human brain (Roth $\&$ Giarman, 1970). It has a structure similar to $\gamma$-aminobutyric acid and has been used as an anaesthetic and in the treatment of narcolepsy (Mamelak et al, 1986) and alcohol dependence (Gallimberti et al, 1989). There have been cases of dependence with withdrawal symptoms (Galloway et al, 1997). I believe this to be the first reported case of in-patient detoxification.

Between October and December 1999 two patients dependent on GHB were admitted to our in-patient unit for detoxification. This report summarises the case history of the first patient admitted. The second patient had a similar history.

A 43-year-old male reported using GHB for 2.5 years. The effects of use were reported as feelings of relaxation, inner well-being, increased appetite and short, restful periods of sleep. Starting doses of GHB were difficult to quantify as it is generally taken in liquid form. The patient said his dose was originally $15 \mathrm{ml}$ irregularly, but had increased to $30 \mathrm{ml}$ every 3 hours by the beginning of 1999. The patient reported withdrawal experiences such as feelings of panic, terror and anxiety, often with a tremor. Other autonomic features included diarrhoea. Adverse effects of GHB were reported, including accidental injury when intoxicated and episodes of bizarre behaviour. In-patient detoxification was thought necessary as both patients were unable to stop using GHB at home.
On admission to the unit physical examination was unremarkable apart from some features of anxiety. Physical investigations were normal. The patient was commenced on a diazepam reducing regime from $20 \mathrm{mg}$ over 11 days. Detoxification was uneventful. The patient was engaged in relapse prevention and referred to psychotherapy services.

Gamma-hydroxybutyrate has adverse effects but also produces euphoria and relaxation; GHB has abuse and dependence potential and so educational campaigns for the public may be important.

Gallimberti, L., Canton, G., Gentile, N., et al (1989) Gamma-hydroxybutyric acid for treatment of alcohol withdrawal syndrome. Lancet, ii, 787-789.

Galloway, G. P., Frederick, S. L., Staggers, F. E. Jr, et al (1997) Gamma-hydroxybutyrate: an emerging drug of abuse that causes physical dependence. Addiction, 92 . 89-96.

Mamelak, M., Scharf, M. \& Woods, M. (1986)

Treatment of narcolepsy with GHB. Sleep, 9. 285-289.

Roth, R. \& Giarman, N. (1970) Natural occurrence of GHB in mammalian brain. Biochemical Pharmacology, 19, 1087-1092.

G. Price South Sefton Community DrugsTeam, 18 Great Georges Road, Liverpool L22 IRB

\section{Suicide in psychiatric hospital in-patients in Ireland}

We were interested in the paper by Powell et al (2000) concerning suicide in psychiatric hospital in-patients. We conducted a 10-year review of the same phenomenon in Irish psychiatric hospitals (Corcoran \& Walsh, 1999). Although this was not a case-control study in the sense of Powell et al, the findings were very similar, particularly in respect of the high proportion of suicides $(70 \%)$ among in-patients who died 'off the premises' although 'on the books'. The Irish suicide rate among acute in-patients (i.e. those in hospital for less than one year), at 319 per 100000 of population $(v .118$ per 100000 for long-stay patients), is higher than that reported by Powell et al (137 per 100000 admissions).

However, the validity of calculating inpatient suicide rates on the basis of an admissions denominator is questionable. It ignores the length of time during which each individual is at risk during a hospital year, and is based on admissions rather than on the individuals contributing to these admissions. Many patients may have had several admissions in any given year. We approached the problem by the person-year method which takes into account not only the number of admissions, but also their mean length of stay and other data which were available to us from the National Psychiatric In-Patient Reporting System. Our paper discusses the imperfections of this approach.

Corcoran, E. \& Walsh, D. (1999) Suicide in psychiatric in-patients in Ireland. Irish Journal of Psychological Medicine, 16, |27-13|.

Powell, J., Geddes, J., Deeks, J., et al (2000) Suicide in psychiatric hospital in-patients. Risk factors and their predictive power. British Journal of Psychiatry, 176, 266-272.

E. Corcoran St Conal's Hospital, Letterkenny, Co. Donegal, Ireland

D. Walsh Inspector of Mental Hospitals and Health Research Board, 73 Lower Baggot Street, Dublin 2, Ireland

\section{Low blood pressure and depression in the elderly}

Paterniti et al (2000) report welcome prospective data showing that low blood pressure precedes depression in older people rather than vice versa. However, important alternative explanations for this effect require consideration before conclusions can be drawn regarding causality.

Poor physical health and disablement have been shown to be strong risk factors for incident depression in older people (Prince et al, 1997). A large prospective community study showed that low blood pressure was associated with raised mortality but that this effect was eliminated after adjustment for comorbid physical illness (Boshuizen et al, 1998). The same may be true for depression. Paterniti et al comment that the number of chronic diseases was measured in participants and was not associated with depressive symptoms or low blood pressure. However, it is the severity of individual conditions and resulting functional limitation which are likely to be most important in depression rather than the number of different conditions. Important confounding effects may therefore have been missed. Both depression and low blood pressure may also be secondary to early cognitive decline, although this is less likely to explain results in the age range of participants for this study.

In order to develop effective strategies for the prevention of depression in later life, 
further research will be required to clarify causal pathways: in particular: (a) whether low blood pressure causes depression through one of the organic mechanisms discussed by the authors; (b) whether low blood pressure and depression are both secondary to early cognitive decline; and/ or (c) whether low blood pressure is a marker for other, more psychological risk factors for depression, such as the impact of poor physical health and functional limitation.

Boshuizen, H. C., Izaks, G. J., van Buuren, S., et al (1998) Blood pressure and mortality in elderly people aged 85 and older: community based study. British Medical Journal, 316, 1780-1784.

Paterniti, S., Verdier-Taillefer, M.-H., Geneste, C., et al (2000) Low blood pressure and risk of depression in the elderly. A prospective community-based study. British Journal of Psychiatry, 176, 464-467.

Prince, M. J., Harwood, R. H., Blizard, R. A., et al (1997) Impairment, disability and handicap as risk factors for depression in old age. The Gospel Oak Project V. Psychological Medicine, 27, 31I-32I.

R. Stewart Section of Old Age Psychiatry, Institute of Psychiatry, De Crespigny Park, London SE5 8AF

\section{Complex medical roles in mental health review tribunals}

Gibson (2000) makes a thoughtful rejoinder to the suggestion by Richardson $\&$ Machin (2000) that the dual nature of the roles exercised by the mental health review tribunal (MHRT) medical member precludes open-mindedness. That this need not be the case was demonstrated some years ago by Langley (1990, 1993) and Brockman (1993). Gibson suggests that the role of the MHRT doctor was introduced in the 1959 Act to facilitate examination of the "hospital notes without ruffling medical feathers". In reality, the issue of the medical member's role was more complex than this. During the parliamentary debates on the 1959 Act there were very conflicting views expressed as to who was best fitted to make judgements concerning the need for detention, bearing in mind the then current legislation which involved a purely judicial decision. A compromise appears to have been reached by the introduction of the present three-member MHRT panel.

Gibson's remedy, which would involve tribunal members reading the medical notes for half an hour prior to the hearing, has two serious weaknesses. First, in many cases the notes are too voluminous and complicated to make this possible in the time-scale suggested. Second, medical notes sometimes require a certain degree of medical interpretation for the benefit of the two non-medical members of the panel. However, these issues may turn out to be academic in the light of the current Government's proposals for reform of the 1983 Act (Department of Health, 1999) involving a considerably more complicated (and, most likely, more costly) system than we have at present; a system which also comes very close to infringing the European Convention on Human Rights' mandates. It is also very clear that the Government's proposals have not found favour with some members of the Scoping Study Review Team (Peay, 2000). There is an old adage 'marry in haste, repent at leisure'. Maybe in this case it would be appropriate to substitute for this phrase, 'legislate in haste' (on the basis of a pre-determined and heavily constrained remit and timescale by Government) and we will be most certain to 'repent at leisure'.

Brockman, B. (1993) Preparing for Mental Health
Review Tribunals: reports and dilemmas. Psychiatric Review Tribunals: repor

Department of Health (1999) Reform of the Menta Health Act, 1983: Proposals for Consultation. London: Stationery Office.

Gibson, A. C. (2000) Medical roles in mental health review tribunals (letter). British Journal of Psychiatry, 176 496-497.

Langley, G. E. (1990) The Responsible Medical Officer and Mental Health Review Tribunals. Psychiatric Bulletin, 14, 336-337.

- (1993) Mental Health Review Tribunals in practice. Psychiatric Bulletin, 17, 331-336.

Peay, J. (2000) Reform of the Mental Health Act, 1983 Squandering an Opportunity. Journal of Mental Health Law, 3, 5-15.

Richardson, G. \& Machin, D. (2000) Doctors on tribunals. A confusion of roles. British Journal of Psychiatry, I76, II0-115.

H. A. Prins Lay Member, Mental Health Review Tribunal, I Home Close Road, Houghton on the Hill, Leicester LE7 9GT

\section{Forensic trials inform the present and future}

Lindqvist \& Skipworth (2000) emphasised the shortage of high-quality randomised trials dealing with the treatment and rehabilitation of mentally disordered offenders and highlighted problems of undertaking such studies. Currently, we are involved in a project, funded by the UK National Health Service Research and Development Programme on Forensic Mental Health, to create a register of randomised controlled trials dealing with the management of violent or aggressive people. Initial searches identified 22000 citations, over 2000 of which were relevant trials. We are now surveying the subset of 350 trials of most interest to the forensic mental health services. Data on content and quality are being reliably recorded and a report will be produced for publication. Already some of these trials are of sufficient quality to be included in systematic reviews (Brylewski \& Duggan, 2000; Fenton et al, 2000; White et al, 2000).

It is likely that Lindqvist \& Skipworth are correct to suggest that high-quality studies are rare. Many trialists, however, have used the 'gold standard' of mental health care evaluation (World Health Organization Scientific Group on Treatment of Psychiatric Disorders, 1991), the randomised trial, to investigate the value of interventions relevant to forensic services. Much can be learnt from such studies, even if they are of limited quality. Systematic appraisal of such work may inform practice, but certainly guides future research. Lindqvist \& Skipworth listed considerable difficulties encountered by trialists of interventions relevant to forensic services. These difficulties have all, to a greater or lesser extent, been considered and addressed, and large, simple randomised trials could overcome most problems. Indeed, many of the treatments commonly used for offenders with mental disorders may be unethical outside of such trials (White et al, 2000).

Brylewski, J. \& Duggan, L. (2000) Antipsychotic medication for challenging behaviour in people with learning disability (Cochrane Review). In The Cochrane Library, Issue 2. Oxford: Update Software.

Fenton, M., Coutinho, E. S. F. \& Campbell, C. (2000) Zuclopenthixol acetate in the treatment of acute schizophrenia and similar serious mental illnesses (Cochrane Review). In The Cochrane Library, Issue 2. Oxford: Update Software.

Lindqvist, P. \& Skipworth, J. (2000) Evidence-base rehabilitation in forensic psychiatry. British Journal of Psychiatry, I76, 320-323.

White, P., Bradley, C., Ferriter, M., et al (2000) Managements for people with disorders of sexua preference and for convicted sexual offenders (Cochrane Review). In The Cochrane Library, Issue 2. Oxford: Update Software.

World Health Organization Scientific Group on Treatment of Psychiatric Disorders (1991) Evaluation of Methods for the Treatment of Mental Disorders. Geneva:

S. J. Cure, C. E. Adams Cochrane Schizophrenia Group, Summertown Pavilion, Middle Way, Summertown, Oxford OX2 7LG 